\title{
A Model to Develop Effective Virtual Teams
}

\author{
Dr Chad Lin \\ CBRCC, Faculty of Health Sciences, Curtin University of Technology, Australia \\ elin123au@yahoo.com.au/c.lin@curtin.edu.au \\ Dr Craig Standing \\ School of Management, Edith Cowan University, Australia \\ c.standing@ecu.edu.au \\ Dr Ying-Chieh Liu \\ Department of Information Management, Chaoyang University of Technology, Taiwan \\ allanliu@cyut.edu.tw
}

\begin{abstract}
A review of the literature shows the factors that impact on the effectiveness of virtual teams are still ambiguous. To address this problem we developed a research design that included a meta-analysis of the literature, a field experiment and survey. The meta-analysis identified factors which impact on the effectiveness of virtual teams which were then validated by a field experiment and survey. The results of the study indicate that social dimensional factors need to be considered early on in the virtual team creation process and are critical to the effectiveness of the team. Communication is a tool that directly influences the social dimensions of the team and in addition the performance of the team has a positive impact on satisfaction with the virtual team. A major contribution of the paper is an integrated model of factors that contribute to virtual team effectiveness.
\end{abstract}

Keywords: virtual teams, performance, satisfaction, communication, cohesion

\section{Introduction}

Despite the level of research interest in virtual teams there is still uncertainty in relation to an integrated set of factors that contribute to virtual team effectiveness. Research has identified the importance of social factors $[28,111]$, task related factors $[16,77]$ and the role of communication $[47,53,108]$. However, testing these factors in an integrated model has proved difficult because of the large number of factors that have been identified in the literature and the difficulties associated with accessing virtual teams. The purpose of this study is to address these issues by identifying the key factors from the literature that impact on virtual team effectiveness and empirically validating an integrated model that will be of use to both researchers and practitioners. 
A wide range of factors have been identified in the literature as impacting on the effectiveness of virtual teams. Features of relationships including the diversity of the team [5], team cohesiveness, team status, and communication within the team [37] are all seen as important. Other factors that impact on team effectiveness include net-centricity [7], team member expertise [68], extraversion of team members and group interaction styles [12]. In addition, some studies have focused on task dimensional factors [18, 70] whilst other research has concentrated solely on social dimensional factors [32, 84]. Given that research studies to date have examined a wide range of factors in isolation, there is now a need to take an integrated approach to virtual team effectiveness that focuses on both task and social dimensional factors [82, 99, 102].

To consolidate and extend the research conducted on virtual team effectiveness our purpose is to identify and examine the key factors which impact on the effectiveness of virtual teams. Effectiveness in this paper relates to the performance and satisfaction of virtual teams. We approach our objective by integrating the results from previous studies on virtual teams using a meta-analysis and from this develop a model for evaluating the effectiveness of virtual teams. The model is then validated through a survey of virtual team participants.

\section{Literature Review}

The Media Richness theory, proposed by Daft and Lengel [35], stated that organizational success is based on the organization's ability to process information of appropriate richness in order to reduce uncertainty and clarify equivocality. Uncertainty signifies the absence of information while equivocality implies ambiguity. It is thought that a greater quantity of information can reduce uncertainty whereas better quality of information can decrease equivocality. Limitations of media in a virtual environment (e.g. virtual teams) may limit the quantity and quality of information. The Media Richness theory underpins the theoretical base of this study due to the lack of face-to-face communication in virtual teams. Therefore, identification of key factors from the literature that impacts on virtual team effectiveness may provide more cues to assist virtual teams in increasing the quantity and quality of information exchanged which, in turn, can lead to reduction in uncertainty and equivocality. 
We define the concept of virtual team as an interdependent group working on a project across time and space relying on information and communication technologies (ICT) [77]. The literature on virtual teams falls into two main categories: firstly, the benefits and problems of virtual working compared with working face-to-face (e.g. $[16,70])$, and secondly, the factors that impact on virtual team effectiveness (e.g. [36, 79, 86]). The focus of our research is the factors that impact on virtual team effectiveness. This research area is characterized by issues related to identifying the most significant factors impacting on effectiveness, the relationships between social and task related factors, the role and significance of communication in virtual team effectiveness and the relationship between performance and satisfaction when working in virtual teams.

\section{Task Dimensional Factors}

The literature on virtual teams has emphasized the task dimensional factors. For example, Bordia [16] and Lipnack and Stamps [77] have found that group members within virtual teams tend to be more task-oriented because of the constraints imposed by computer mediated communication (CMC). A brief description of the task dimensional factors impacting on virtual team effectiveness follows.

In general, periodic face-to-face (FTF) meetings may improve project progress [86]. However, if FTF meetings are not feasible, communicating and exchanging information through CMC typically improves the coordination of virtual teams [83]. Coordination implies the sharing of goals and creation of something new [71] and it has also been linked to the performance of teams [63, 79]. Kraut et al. [73] studied the use of electronic networks and personal relationships in the coordination of relationships between buyers and suppliers. The results show that coordination in an electronic network is most suited to routine work. Coordination can also play a positive moderation role in conflict management and team performance [90]. In addition, there was no significant difference between the qualities of the decisions for teams utilizing text-only versus audio-only communication but adding video to audio-only communication resulted in a significant improvement in the quality of teams' strategic decisions [11].

Task-technology-structure fit, another task dimensional factor, evaluates the fit between task, technology, and structure. It determines the tasks suitable for various technologies and structures as well as the technology 
acquired by virtual team members to develop a new structure over time [70, 102]. Generally speaking, FTF meetings fit more ambiguous tasks whereas in a virtual team environment, for example, more structured tasks such as routine analysis or monitoring project status are more appropriate [102].

\section{Communication}

It has been argued that efficiency in CMC is lower than FTF communication due to the lack of speech acknowledgements and the fact that CMC consumes more time in explaining the conversation context [17, 3],

[108]. It has been recognized that some tasks may not be suited to CMC. For example, problem solving tasks are considered unsuitable for CMC because they require substantial interaction and this can even apply to some problems of low complexity [115].

When CMC relies heavily on text significant information is often not communicated within a message.

Successful communication demands the foundation of mutual knowledge and parties typically use physical and linguistic expression to make inferences about others' knowledge [53] that is difficult to communicate with text alone. In addition, text messages may take more time to comprehend for the recipient because of the absence of visual cues and linguistic expression.

Despite the disadvantages of CMC, the evaluation of others is less stereotyped and more valid when visual observation is removed from communication [117]. Also, asynchronous communication in virtual teams may be more effective in some aspects since communication can take place over an extended period of time. The delay between response and feedback can provide members with the opportunity to think about the problems and reflect more efficiently before responding [38].

\section{Social Dimensional Factors}

The effect of social factors on the performance and satisfaction of virtual teams have been recognized. Social factors such as relationship building, cohesion, and trust are crucial for the effectiveness of virtual teams [28], $[47,111]$. CMC has been found to promote the exchange of social cues to build interpersonal relationships 
between team members in the early development of virtual teams $[29,8,86,104]$ as well as to foster cohesion among team members [26]. Relationship building and cohesion have been associated with better performance and satisfaction in virtual teams $[81,86,102]$.

Relationship building can strengthen feelings of inclusiveness or a sense of belonging to teams and further foster cohesion [102]. The Time-Interaction-Performance theory developed by McGrath [88] proposed that a supportive group ethos and group well-being are directly related to developing relationships in virtual teams. Sawyer and Guinan [111] studied 40 software development teams and found that social process skills (such as the ability to resolve conflict) is more important than task skills (such as use of automated development tools) in project quality and team performance. Social process skills account for more than 25 percent of variation in software product quality. Janz et al. [58] surveyed 231 IS professionals from 27 systems development teams across 13 organizations and found that mission clarity, team collaboration and team unity is predictive of improved work outcomes, increased job satisfaction, satisfaction with personal growth and worker motivation. Ward and Tracey [126] reported that individuals involved in an online relationship have higher computer confidence. Pauleen [96] studied seven virtual team leaders from several New Zealand organizations and developed a framework to strengthen the relationship of virtual team members. One key component of the framework is the preparation of relationship building prior to the commencement of a project. From these studies, it can be seen that the relationship building is of great importance in a virtual environment.

Cohesion has been considered to be the most important small group variable [78]. Team cohesion is the degree to which team members identify with each other and with the group as a whole [27, 30], and the level of group integration [27] and has been found to have a positive relationship with group performance [28] and satisfaction [81, 86]. Perception of cohesion by group members is recognized as influencing members' behaviour and has two dimensions: sense of belonging and feelings of morale [15]. Two major models have been developed to measure cohesion: unidimensional model and multidimensional model. The unidimensional model measures cohesion in single dimension [20]. The multidimensional model measures cohesion in multi-dimension and 
several researchers have indicated that multidimensional models have more potential than unidimensional models in evaluating what is known about cohesion (e.g. [27]).

Trust

The concept of "trust" in virtual teams has been widely researched [42, 91, 104, 68]. Many dimensions of trust have been identified including cognitive trust, calculative trust and institutional trust [75]. Studies have been carried out to examine trust in relation to the abilities, benevolence and integrity of team members [85]. A correlation has also been established between personal bonding and shared experiences and levels of trust [34]. Initial trust among virtual team members is critical $[61,104]$. Empirical studies have given support to the concept of swift trust in temporary work arrangements [89] and in successful temporary virtual teams [61]. However, recent findings suggested that building trust in a virtual environment is problematic due to the fact that team members usually have no common past and no future to reference as a base to build trust, and have never even met face-to-face in the past $[49,92]$. In addition, many of the items used to analyze trust in virtual teams overlap with the items used in other constructs such as relationship building and cohesion.

There are factors that have not been studied as extensively as the above-mentioned factors [102]. Some of these factors have often been referred to as "input factors" (e.g. culture, design, and technical expertise) [102]. Culture is an important issue in a virtual team environment when team members are in different countries or have different cultural backgrounds [130]. Design and technical expertise relate to the subjects, environments, and technologies $[98,127]$. Several studies have suggested that the results of design and technical expertise should be examined in terms of other setting such as different population and different problems [124] and that future research should focus more on expertise, authority, and power [23].

\section{Performance and Satisfaction}

Performance and satisfaction represent the two major measures of effectiveness of virtual teams. Piccoli et al. [98, p362] defined effectiveness in terms of "group-produced outputs and the consequences a group has for its members”. Effective teams should be able to produce higher quality output and reward team members in terms of gratification and satisfaction with the working experience [59]. Performance can be defined as the extent to 
which the group's outputs meets the required standards or measures [81] while satisfaction can be seen as the extent of the members’ perception of decision and agreements with the eventual outcomes [30].

The measurements of performance and satisfaction in virtual teams are diverse (e.g. [121, 124]. From the existing literature, performance can be categorized into three types: grader/ranking, discussion board/videotape, and questionnaires. Graders are engaged in scoring the outcome (e.g., group report). For example, lecturers or experts scored the students' group assignment [45]. Ranking has two sources: individual/group ranking [127]. Discussion board/videotape is used by [13] and the data from discussion board is analyzed for group process of virtual teams. Questionnaires can be evaluated by focusing on perceived quality, such as meeting quality and perceived project quality [45], perception of discussion quality [13], perception of learning effects, decision quality and perceived level of teamwork [93].

The methods of evaluating satisfaction are more in agreement. The two main aspects of satisfaction are "satisfaction with the process" [93] and "satisfaction with the outcomes" [93, 127]. Further measurements of satisfaction have been identified, such as fairness and solution confidence.

\section{Research Methodology and Design}

This research adopted a pluralist (3-stage) approach (Figure 1). The use of multiple methods (triangulation) such as surveys and field experiment increases the reliability of the study. The first stage of this study engaged meta-analysis to develop a preliminary framework for evaluating the effectiveness of virtual teams. The second stage of this study employed the field experiment to study the preliminary framework. The third stage involved the use of survey to validate and further refine the preliminary framework developed earlier.

$<$ Figure 1: The research process $>$

\subsection{Stage 1: Meta-analysis}

A meta-analysis is a set of procedures that combine many results of individual studies and applies statistical analysis to retrieve the general conclusions without requiring access to original study data [4]. It is suitable for examining causal relationships and theories, and can be used to build theoretical frameworks [56] in the IS 
discipline [57]. A meta-analyse has several potential strengths. Firstly, a meta-analysis is able to represent the "big picture” of a certain topic by increasing the sample size to strengthen statistical power. Thus, the result of analysis could yield more generalizable conclusions than individual studies [56]. Secondly, a meta-analysis enables the researcher to be familiar with a specific topic quickly and efficiently. Finally, a meta-analysis can identify the inconsistencies between different studies and test hypotheses about factors that may be moderators or mediators.

There are several meta-analysis methods but Hunter and Schmidt’s (HandS) method [56] has proved the most popular approach. We use this method to identify the factors which affect the effectiveness of virtual team from the existing literature. The HandS method (Figure 2) focuses on correlative studies and it proposes that all kinds of statistics should be transferred to correlation I. Due to its consideration of sampling error, measurement error, range variation, and confidence interval, it can ensure the statistical independence among the effect sizes and reduce the errors occurred by different measurements and studies [56].

<Figure 2. The Hunter and Schmidt’s method of meta-analysis (Source: [56])>

According to the HandS's method, increasing sample size can boost the statistical power and choosing wider sources of literature can avoid bias caused by different publications. Thus, this study has collected literature data in three dimensions:

(1) Studies that discuss the factors that affect the effectiveness of virtual teams;

(2) Studies that relate to the comparison of Face-to-Face (FTF) communication and

Computer-Mediated-Communication (CMC) in virtual teams (but only the CMC data are used); and

(3) Studies that discuss Decision Support System (DSS) in virtual teams or online discussion.

The studies chosen within these three dimensions identified factors that were related to the performance and satisfaction of teams through the use of computer technology to communicate in order to finish certain tasks. This study used keywords such as "virtual teams”, “computer mediated communication” and "decision support” to identify related studies published in the ABI/Inform Proquest, EBSCO, and ScienceDirect databases during 
1980-2007. A total of 251 studies were found to satisfy the above three criteria. Then, two further criteria were applied to locate the most relevant studies:

- $\quad$ The study must have provided correlation coefficient; and

- The independent and/or dependent variables (in relation to the performance and satisfaction of teams) used in these studies must be closely related to the terms identified in the literature.

The list was reduced to 50 after applying the above two criteria. The variables of these 50 studies (out of 251 studies examined earlier) were further analyzed and were categorized in accordance with key constructs from the literature. These studies were independently read and coded by the researchers on the basis of the variables identified. To ensure uniformity, consistency and completeness, data were recorded on pre-designed coding sheets and where there were discrepancies in the interpretation of responses to the questions these were resolved by consultation between the researchers. The Cohen's Kappa statistic was used to analyze the level of correspondence between the researchers and there was a high degree of reliability between the researchers in relation to the interpretation (0.89). This is well above the $61 \%$ level suggested for a substantial strength of agreement [43]. Next, the correlation coefficients were extracted from the study. Appendix 1 shows the correlation coefficients collected from these 50 studies.

Some studies included more than one experiment. In this case, these experiments are considered as separate experiments. For example, Chang [28] engaged in two experiments that have different amount of participants and held in different time, but have the same procedures. Thus, the two experiments are regarded as two individual experiments.

The aim of the meta-analysis is to develop a preliminary framework to evaluate the effectiveness of virtual teams. For this purpose, the best way is to find a broad, existing framework and then assess the relationships between variables. Correlation coefficients have been used extensively as an index of the relationship between two normally distributed variables. The correlation coefficient is therefore a natural candidate as an index of effect magnitude suitable for accumulation across studies and is used in this study [52]. 
After the selection of the variables and studies as described earlier, the meta-analysis followed the guidelines set out by Hedges and Olkin [52] and Hunter and Schmidt [56]:

(1) Arrange correlation coefficient - this step includes categorization of variables' relationships, and development of frequency distribution tables for the relationships of these variables (Appendices 1 and 2);

(2) Conduct heterogeneity test - the main purpose of a heterogeneity test is to check the heterogeneity between each effect size and calculate the Q-value [52]. The higher the Q-value, the higher is the heterogeneity. Meta-analysis software (Comprehensive Meta Analysis) was used to conduct this test and other tests (see Appendix 3);

(3) Calculate fixed and random effects - choosing a fixed effect model implies that the samples are from the same population [40]. Thus, if the sample of each study is unlimited, the effect size of each study will be the same. However, this leads to results with a large Q-value and biases the test. On the other hand, random effect models assume that the populations of the samples are different. If the sample of each study is unlimited, the effect size of each study will not be the same. It shows the data as a distribution instead of an estimation of single value. The random effect distribution is commonly supposed to be a normal distribution;

(4) Choose the appropriate effect model - The choice of model relates to the significance of the Q-value.

Differences in results between the fixed effect and random effect models may be caused by differences in quality of the studies and it may be necessary to exclude certain publications. If the Q-value is too big, the random effect model should be chosen instead of the fixed effect;

(5) Test the significance of variables' relationships - In the final stage of meta-analysis, the significance of variables' relationships are tested by estimating the confidence interval. If the confidence interval is not 0 , then the variables’ relationships are significant at the 95\% confidence level.

\subsection{Stage 2: Field experiment}

A field experiment is a method that involves experimental design but without experimental controls and manipulation of independent variables and is carried out in the natural settings of the phenomenon of interest. Field experiments, through the involvement of real team members, are particularly useful for studying novel, 
variable and less understood situations, such as in the factors which impact on virtual team success [106]. In a field experiment, few variables are controlled and the participants interacted in a natural setting. Although the lack of controlling variables may cause some difficulties in duplicating and affecting the results of the project in the future, field experiments can lead to high generalizability (external validity) of results and construct validity [65].

This research designed a project that gave a task for the participants to finish in a natural setting and the participants needed to hand in reports at the end of the task. The field experiment was used to explore the problems and factors that affect the effectiveness of virtual teams as well as to discover ways of improving the effectiveness of virtual teams. Lecturers in business faculties of all four Western Australian universities were contacted to nominate their business undergraduate or postgraduate students to take part in the field experiment. In total, 200 students were recruited. They were all familiar with basic computer technology such as the Internet, word processing, and MSN Messenger. Students from different universities were chosen randomly to form a virtual team. Twenty-five virtual teams with eight members each were formed and efforts made to ensure that none of the team member knew other team members before their team was formed. The teams worked on several team building exercises to get to know one another via MSN Messenger before working on the group tasks. MSN Messenger was chosen as the tool to communicate between participants due to its popularity, powerful functions, prevalence and convenience.

The formal stage of the field experiment involved a judgment task that had to be reported. A judgment task is a highly interdependent task and it can be used to promote the participants' conversation and interaction [87]. A fictitious and controversial case was given to the team members as the judgment task. The case is about a famous BBQ restaurant facing some serious problems and challenges such as the lack of the ability to manage customer orders, the use of inappropriate stock ordering system, and the difficulties in managing human resource issues. Each group was asked to find the solutions for the restaurant with a limited time and budget. In addition, team members could only communicate with other group members via the MSN Messenger, and any other methods of communication were prohibited. The use of voice and web camera conversation modes was prohibited as well. 
Participants were only allowed to communicate through text mode to complete the assigned tasks. They were explicitly warned that their MSN Messenger log files would be analyzed to determine whether or not their tasks were completed without communicating face-to-face. At the end of the field experiment, each group had to hand in a report and MSN Messenger log files.

\subsection{Stage 3: Survey}

Following the completion of the field experiment, all participants were asked to fill out a questionnaire. A survey was chosen because it allows for systematic gathering of information from participants for the purpose of understanding and predicting some aspects of the behavior of the population of interest. Participants were asked to use a 7-point Likert scale in answering the questions related to the preliminary framework developed and space was left to allow for further comments to be made. Two follow-up mailings and/or telephone calls were carried out to increase the response rate. In total, 198 questionnaires were returned. The questionnaire was composed of eight main parts and the measurement items were all related to the six variables (constructs) identified earlier (Figure 4): communication, relationship building, cohesion, coordination, performance, and satisfaction. All of the measurement items in the questionnaire were taken from previous studies (Table 1). <Table 1. Measurement items and scale reliabilities of variables $>$

\section{Results}

\subsection{Meta-analysis}

As mentioned earlier, 50 studies from 251 which satisfied the criteria specified were selected and their correlation coefficients were extracted (see Appendix 1). A frequency distribution table (Appendix 2) was developed and revealed 35 relationships between variables. In addition, it can be seen that the proportion of variables with frequency equal to "1" is 19/35. This suggests that there are potentially a large number of factors which impact on virtual team performance but many of which may not be critical. Only a limited number of studies have explored the interaction between social and task factors and the factors' interactive effect on the performance and satisfaction of virtual teams [22, 23]. Undoubtedly, this is one area that requires further research. We examine these relationships by developing an integrated model of virtual team effectiveness which includes both social and task factors as well as shows the influence of these factors' on the effectiveness of 
virtual teams.

Only relationships with two or more occurrences were incorporated into the final meta-analysis giving a total of 16 relationships to be analyzed.

The outcome of the meta-analysis on these 16 relationships from the literature is shown in Appendix 3. The analysis found 8 significant relationships (Table 2).

Table 2. Eight significant relationships

The model resulting from the meta-analysis is shown in Figure 3. It was found that only 5 factors (relationships building, cohesion, trust, communication and coordination) had affected the performance and satisfaction of virtual teams. Other factors such as task-technology-structure fit, culture, design, and technical expertise were found to have no significant impact on performance and satisfaction of virtual teams. Furthermore, there was no relationship between these 5 factors and the correlations between relationship building and coordination, and communication and coordination were found to be insignificant.

<Figure 3. The preliminary model for evaluating the effectiveness of virtual teams $>$

The analysis of literature revealed that one of the variables, trust, is a factor relying on several constructs (relationship building, cohesion, communication, coordination) which already exist in the model [60, 75]. Hence, trust was excluded from the model as a discrete variable.

\subsection{Hypotheses}

Both social (e.g. relationship building and cohesion) and task (e.g. coordination) factors are crucial for improving the performance and satisfaction of virtual teams [63]. Several studies have found that some relationships existed between these factors and the performance and satisfaction of virtual teams [16, 102]. At the center of virtual team development process is communication. Communication in CMC has been found to promote interpersonal relationships between team members in the early development of virtual teams [86, 104]. By building closer interpersonal relationships among team members early, it is possible for virtual teams to achieve more success later $[67,113]$.Therefore, the first hypothesis is as follow: 


\section{H1 Communication is positively related to relationship building.}

Group cohesion is an important factor to be considered for virtual teams [107]. Virtual teams need to put in more efforts in communication than FTF teams to develop the same degree of group cohesiveness [99]. While there has been other contradictory findings, it has been generally accepted that virtual team members tend to communicate enough social information to develop strong cohesion over time [22, 30]. This has suggested that there is a positive linkage between communication and cohesion within virtual teams $[99,125,127]$. Thus, the second hypothesis is derived:

\section{H2 Communication is positively related to cohesion.}

Several studies have found that virtual teams tend to place more emphasis on the task dimensional factors than FTF teams [16, 77]. In addition, virtual team members generally have weaker interpersonal relationships than FTF teams [23, 127]. Therefore, closer interpersonal relationship among members early in virtual team projects might foster the ability to coordinate the tasks better:

\section{H3 Relationship building is positively related to coordination.}

Similarly, group cohesion can lead to virtual teams being better at coordinating project tasks [36]. Virtual teams are often self-managed without a designated leader and therefore may be less efficient in coordination [123] and require certain intervention [90]. Thus, group cohesion might play a big role in remedying this situation as successful coordination in virtual teams requires concerted efforts in tracking progress and tasks, and accounting for outcomes as well as melding the team together [77, 110]:

\section{H4 Cohesion is positively related to coordination.}

Exchanging information through CMC fosters the coordination of virtual teams [86]. Coordination constitutes the degree of effort between the team members to manage collective resources and the extent to which the work activities of team members are logically consistent and coherent [99, 102]. Coordination has been associated with positive virtual team performance [63, 86]:

\section{H5 Coordination is positively related to performance.}

Performance of virtual teams has become an important factor for determining satisfaction of team members [70], $[99,119]$. However, much of the work so far has been done on who (e.g. women vs men) is most satisfied within the virtual teams (e.g. [76]) and relatively little work has been carried out to examine what (e.g. performance) 
makes team members satisfied with the virtual team experience [102]. Therefore, we seek to examine whether the performance of the virtual teams is strongly associated with increased satisfaction of team members:

\section{H6 Performance is positively related to satisfaction.}

Hypotheses 3 and 5 test the relationships between the two causal variables (relationship building and coordination) and one effect variable (performance). Driskell and Radtke [37] found that prior research on virtual teams paid too much attention to the development of advanced technological environments instead of considering the social and psychological dimensions. Social factors such as relationship building, cohesion and task factors such as communication and coordination might mutually impact on the effectiveness of virtual teams.

Hypotheses 1, 2, 3 and 4 examine the relationships between the four causal variables (communication, relationship building, cohesion, and coordination). Hypotheses 1 and 2 are proposed to see if communication affects social factors (relationship building and cohesion). Hypotheses 3 and 4 examine the relationships between the social and task factor (relationship building, cohesion and coordination). An integrated model of virtual team effectiveness is shown in Figure 4.

$<$ Figure 4. An integrated model of virtual team effectiveness $>$

\subsection{Field Experiment}

A field experiment was conducted to examine the revised framework developed by meta-analysis and to prepare for the subsequent survey. Participants’ MSN Messenger log files were analyzed to ensure that they did not communicate face to face and that their tasks were completed using MSN Messenger in text mode.

From the analysis of the MSN Messenger log files, some interesting findings were observed. First, the average post of all teams was 420 sentences and there were 5.1 words per sentence. Therefore, sentences transmitted via MSN Messenger were generally short. One reason for this was the frequent use of abbreviations and acronyms, such as BTW (by the way), BRB (be right back), and CU (see you). Another possible reason was that many redundant words were discarded before entering into the MSN Messenger through slight deliberation. Second, there was no positive relationship between the amount of the conversation sentences posted and the team 
performance. In other words, simply exchanging more information and data within each participating group would not necessarily lead to higher performance if they did not facilitate the progress of the project.

\subsection{Survey}

The average age of the respondents was 24.50 , with a range of 20 to 31 . The sample was 47.69 percent male (n=93) while 52.31 percent female ( $n=102$ ). Respondents were asked to indicate their agreement on a seven-point Likert scale ( 1 for strongly disagree and 7 for strongly agree) with statements concerning six main constructs: (1) relationship building; (2) cohesion; (3) communication; (4) coordination; (5) performance; and (6) satisfaction. Prior to analysis, data were screened for possible response sets, outliers, and missing or out-of-range values. Three questionnaire containing missing or incomplete values were discarded, leaving a usable sample of 195 for analysis. The reliability analysis (alpha) was conducted on these six main constructs. Cronbach’s alphas and measurement for all constructs are provided in Table 3 with all above 0.70 indicating an acceptable reliability of the measures. Table 3 presents the descriptive statistics and covariance for the variables used in this study.

Table 3. Covariance Matrix for Constructs

All measures were analyzed for reliability and validity in accordance with the guidelines set out by Jöreskog and Sörbom [64]. The reliability of these constructs was evaluated using Cronbach's coefficient alpha $(\alpha)$ and their $\alpha$ values were all above 0.70 (see Table 1). An $\alpha$ value of 0.70 or above indicates a reliable measurement instrument. SEM (Structural Equation Modeling) was applied to estimate direct and indirect effects using LISREL 8.72. Confirmatory factor analysis was used to construct a measurement model composed of these constructs using maximum likelihood in LISREL. All variables within the model were regarded as separate reflective measures. The resulting fit indexes indicated that the measurement model fitted the data well. Figure 5 showed the results of the Structural Equation Modeling (SEM) for the constructs. The overall fit of the proposed structural model was quite satisfactory (e.g. $\chi 2=230.07, \mathrm{df}=133, \mathrm{p}<0.001$, Root mean square error of approximation (RMSEA) $=0.06$, Comparative fit index $(\mathrm{CFI})=0.98$, Normed fit index $(\mathrm{NFI})=0.96$, Goodness-of-fit index $(\mathrm{GFI})=0.89$, and Adjusted goodness of fit index $(\mathrm{AGFI})=0.84)$. Although $\chi^{2}$ is a bit large $\left(\chi^{2}=216.78\right)$, the value of (Chi-square/degree of freedom) is less than 2 [31] and the GFI and AGFI are close to 0.90 [50]. In addition, the RMSEA value is only slightly greater than 0.05 (RMSEA=0.06) but still under the acceptable value of 0.08 . The 
above figures imply good model fit [19]. Moreover, the ranges of all factor loadings and the measurement errors were acceptable and significant at alpha $=0.001$, which provided evidence of convergent validity.

<Figure 5. Structural Equation Model Results (H1 through H6)>

Three types of validity were assessed to validate our measurement model: content validity, convergent validity, and discriminant validity. Content validity was established by ensuring consistency between the measurement items and the extant literature. This was done by interviewing communication and virtual team experts and pilot-testing the instrument. Churchill [33] has suggested that convergent and discriminant validities should be examined for construct validity. Therefore, we assessed convergent validity by examining composite reliability and average variance extracted (AVE) from the measures [50]. CR is calculated by squaring the sum of loadings, then dividing it by the sum of squared loadings, plus the sum of the measurement error whereas the AVE measures the variance captured by the indictors relative to measurement error. Our CR values of the six antecedent constructs were between 0.74 and 0.93 and all are above the suggested minimum of 0.70 [50]. Their AVE values were all above 0.50 and these values provided further evidence of convergent validity [44] (see Table 4). These AVE values could also be used to assess discriminant validity [44] which was evident in the results of this study as AVE values for six antecedent constructs were higher than the variance due to measurement error (0.50) [42].

\section{Research Findings}

\section{Hypotheses examination:}

Six significant relationships were found by using LISREL,: communication and relationship building, communication and cohesion, relationship building and coordination, cohesion and coordination, coordination and performance, and performance and satisfaction (Figure 5). All hypotheses (H1, H2, H3, H4, H5, and H6) were supported (see Table 4).

Table 4. The six proposed research hypotheses

\section{Total/ Direct/ Indirect Effects:}

According to the results, performance was directly affected by coordination and the paths that affected performance were: (1) communication $\rightarrow$ relationship building $\rightarrow$ coordination $\rightarrow$ performance; and (2) communication $\rightarrow$ cohesion $\rightarrow$ coordination $\rightarrow$ performance. Satisfaction was affected by performance directly 
and the paths that affected satisfaction were: (1) communication $\rightarrow$ relationship building $\rightarrow$ coordination $\rightarrow$ performance $\rightarrow$ satisfaction; and (2) communication $\rightarrow$ cohesion $\rightarrow$ coordination $\rightarrow$ performance $\rightarrow$ satisfaction (Figure 7). The total/ direct/ indirect effects are shown in Table 5.

Table 5. Total/ direct/ indirect effects

\section{Discussion}

This study makes four key contributions to research on virtual teams. Firstly, the study has presented and validated an integrated model of virtual team effectiveness. This model can be used as a strategic tool in the development, management and evaluation stages in projects that include virtual teams. Secondly, the study has found that social aspects of virtual team development are critical to their performance and satisfaction and must be considered at the outset of the virtual team development process. Thirdly, communication is a tool that directly influences the social dimensions of the team. Fourthly, the performance of the team has a positive impact on satisfaction with the virtual team.

This research study fills the gap in the literature as it for the first time defines the significant factors and their relationships in an integrated model. The virtual team model presented validates the significance of factors related to both social and task dimensional factors identified in the meta-analysis. Past studies on the relationship between the task dimensional factor, communication, and the performance and satisfaction of virtual teams have produced mixed results (e.g. [6, 72, 74]. The results of this study show that communication has significant and direct impact on relationship building and cohesion. This finding is plausible given that communication is instrumental in both task and social dimensions.

The second major contribution is in relation to the importance of social factors in the process of achieving effectiveness in virtual teams. The social dimensional factors of relationship building and cohesion have significant impact on the task factor of coordination which in turn has a direct influence on the performance and satisfaction of virtual team. It can be said that developing successful social relationships can improve the coordination of tasks and so social factors need to be considered as a pre-requisite to effective task coordination. 
The literature has emphasized the importance of task factors such as coordination and under-emphasized the role and significance of social determinants $[37,63,90]$. Our results show that relationship building and cohesion of the group are very important for virtual teams to be effective in accomplishing tasks.

Studies have suggested that cohesion and relationship building are harder to develop in virtual teams because computer mediated communication is generally deficient in the social cues required to build relationships, even when using video conferencing [93]. In addition, teams working in a computer mediated context tend to have higher levels of conflict [124].

In our model, communication directly impacts on relationship building and cohesion but does not directly influence coordination. This is because communication is a process of developing the social dynamics of a group and by default impacts on the task coordination [120]. In other words, the social processes within teams cannot be separated from the tasks to be accomplished. All tasks require some social context and communication is a means to create a social environment in which tasks can be performed.

The performance of virtual teams had a positive impact on the satisfaction with the virtual team in terms of the ability of the group, commitment to the group and confidence in the group. When the outcomes of a virtual team are strong then satisfaction with the team is also high [59]. This is likely to produce a further positive impact on performance, although this is not included and tested within our model.

\section{Managerial implications}

The SEM results indicated that social dimensional factors (i.e. relationship building and cohesion) had stronger relationships (Table 5) with the performance of virtual teams than the task dimensional factor (i.e. coordination). This implies that social dimensional factors such as effective relationship building and cohesion exercises were more important for improving the performance of virtual teams. We suggest that emphasis should be put on building relationships and social cohesion in the initial stage of the virtual project. It is critical that managers build stronger relationships and cohesion among virtual team members as they have significant impact on the 
performance and satisfaction of virtual teams. Various techniques could be employed to improve relationships and cohesion. For example, creating an exercise that focuses on improving the social dynamics of the group would have a beneficial impact on the effectiveness of the team. This could take the form of team members disclosing information about themselves, their expectation for the team and developing social protocols for resolving conflict. Periodic conference calls or face-to-face meetings would also be beneficial to nurture such relationships and increase cohesion within the virtual teams.

\section{Limitation and future research directions}

The evaluation framework of virtual teams developed earlier had made an initial attempt to identify the relationships between those factors that were seen as the most critical in the literature. The meta-analysis had focused only on published refereed journal papers and had omitted conference and working papers. In addition, due to the requirements of conducting a meta-analysis, (the chosen study must provide correlation coefficients or t-value), some important studies may have been excluded from this research. Therefore, it is possible that some factors (e.g. trust, design, and culture) which were excluded from the framework could be important for evaluation of virtual teams. In particular, trust warrants further research as it is such an important and complicated factor.

Moreover, the influence of time on the performance and satisfaction of virtual teams should be also considered in a future study. For example, future research can be conducted to examine whether or not coordination can mediate the effects of communication on the effectiveness (i.e. performance and satisfaction) of virtual teams.

\section{Conclusion}

This study had first identified several social and task dimensional factors (i.e. relationship building, cohesion, and coordination) which had affected the effectiveness (performance and satisfaction) of virtual teams via the meta-analysis. A field experiment was then set up to examine these factors and their relationships. A survey was conducted to validate these relationships in the context of the evaluation model of virtual teams developed earlier, using SEM (Structural Equation Modeling). The results indicated that (1) communication had no significant 
direct impact on the effectiveness of virtual teams; (2) virtual teams focused more on social dimensional factors than the task-oriented factor; (3) social dimensional factors could only affect the satisfaction of virtual teams indirectly through their performance; and (4) there was no significant relationship between the task dimensional factor and the effectiveness of virtual teams. The final evaluation model shows the "Big picture" of virtual teams and illuminates the research directions for the future and in addition provides a guide for the management of virtual teams.

\section{Acknowledgements}

The authors would like to thank all the participants for their assistance and cooperation for this study. In addition, the authors would like to thank the three reviewers for their constructive comments. Finally, we would also like to acknowledge the financial support provided by a research grant from the Faculty of Business and Law, Edith Cowan University.

\section{References:}

[1] A. H. Abdul-Gader, Determinants of computer-mediated communication success among knowledge workers in Saudi Arabia, The Journal of Computer Information Systems 38(1) 55-66 (1997).

[2] P. Agarwal and J. Prasad, The role of innovation characteristics and perceived voluntariness in the acceptance of information technologies, Decision Science 28(3) 557-582 (1997).

[3] H. J. Ahn, H. J. Lee, K, Cho, and S. J. Park, Utilizing knowledge context in virtual collaborative work, Journal of Decision Support System 39(4) 563-582 (2005).

[4] M. Alavi, and E. A. Joachimsthaler, Revisiting DSS Implementation Research: A Meta-Analysis of the Literature and Suggestions for Researcher, MIS Quarterly March 95-116 (1992).

[5] D. G. Ancona, and D. F. Caldwell, Demography and design: Predictors of new product team performance, Organization Science 3(3) 321-341 (1992).

[6] T. J. Andersen, The performance effect of computer-mediated communication and decentralized strategic decision making, Journal of Business Research 58(8) 1059-1067 (2005).

[7] F. F. Anderson and H. M. Shane, The impact of netcentricity on virtual teams: The new performance challenge, Team Performance Management 8(1/2) 5-12 (2002). 
[8] J. B. Arbaugh and R. Benbunan-Fich, The importance of participant interaction in online environments, Decision Support Systems 853-865 (2007).

[9] K. A. Arnold, J. Barling and E. K. Kelloway, Transformational leadership or the iron cage: Which predicts trust, commitment and team efficacy? Leadership and Organization Development Journal 22(7/8) 315-320 (2001).

[10] B. A. Aubert, \& B. L. Kelsey, Further understanding of trust and performance in virtual teams, Small Group Research 34(5) 575-618 (2003).

[11] G.. Baker, The effects of synchronous collaborative technologies on decision making: A study of virtual teams, Information Resources Management Journal 15(4) 79-93 (2002).

[12] P. Balthazard, R. E. Potter and J. Warren, Expertise, extraversion and group interaction styles as performance indicators in virtual teams, Database for Advances in Information Systems 35(1) 41-64 (2004).

[13] R. Benbunan-Fich, S. R. Hiltz and M. Turoff, A comparative content analysis of face-to-face vs. ALN-mediated teamwork. Paper presented at the Proceedings of the 34th Hawaii International Conference on System Sciences (2001).

[14] T. Blomquist, M. Hallgren and A. Nilsson, Development of virtual teams and learning communities. Paper presented at the Formatex, Spain. (2005).

[15] K. A. Bollen, R. H. Hoyle, Perceived cohesion: A conceptual and empirical examination, Social Force 69(2) 479-504 (1990).

[16] P. Bordia, Face-to-face versus computer-mediated communication: A synthesis of the experimental literature, The Journal of Business Communication 34(1) 99-120 (1997).

[17] M. R. S. Borges, P. Brezillon, J. A. Pino, and J. C. Pomerol, Dealing with the effects of context mismatch in group work, Decision Support Systems 43(4) 1692-1706 (2007).

[18] J. Bradley, B. J.White and B. E. Mennecke, Teams and tasks: A temporal framework for the effects of interpersonal interventions on team performance, Small Group Research 34(3) 353-387 (2003).

[19] M. Brown, and R. Cudeck, Alternative ways of assessing model fit. In: K. Bollen and J. Long, Editors, Testing structural equation models (Sage, London 1993).

[20] S. H. Budman, S. Soldz, A. Demby, M. Davis and J. Merry, What is cohesiveness? An empirical 
examination, Small Group Research 24(2) 199-216 (1993).

[21] J. K. Burgoon, and B. A. L. Poire, Nonverbal cues and interpersonal judgments: Participant and observer perceptions of intimacy, dominance, composure and formality, Communication Monographs 66(2) 103-124 (1999).

[22] K. Burke, and K. Aytes, A longitudinal analysis of the effects of media richness on cohesion development and process satisfaction in computer-supported workgroups. Paper presented at the Proceedings of the Thirty-First Hawaii International Conference on System Sciences, (1998).

[23] K. Burke, and L. Chidambaram, Do mediated contexts differ in information richness? A comparison of collocated and dispersed meetings. Paper presented at the Proceedings of the Twenty-Ninth Hawaii International Conference, (1996).

[24] A. Caballer, F. Gracia, and J. M. Peiro, Affective Responses to work process and outcomes in virtual teams: Effects of communication media and time pressure, Journal of Managerial Psychology 20(3/4) (2005).

[25] S. A. Carless, and C. D. Paola, The measurement of cohesion in work teams, Small Group Research 31(1) 71-88 (2000).

[26] A. V. Carron, L. R. Brawley, and N. W. Widmeyer, The Group Environment Questionnaire Test Manual. (USA: Fitness Information Technology 2002).

[27] A. V. Carron, W. N. Widmeyer, and L. R. Brawley, The development of an instrument to assess cohesion in sport teams: The Group Environment Questionnaire, Journal of Sport Psychology 7 244-266 (1985).

[28] A. Chang, and P. Bordia, A multidimensional approach to the group cohesion-group performance relationship. Small Group Research 32(4) 379-405 (2001).

[29] M. Chen, Y. Liou, C. Wang, Y, Fan and Y. P. J. Chi, TeamSpirit: Design, implementation, and evaluation of a Web-based group decision support system, Decision Support Systems 43(4) 1186-1202 (2007).

[30] L. Chidambaram, Relational development in computer-supported groups, MIS Quarterly 20(2) 143-165 (1996).

[31] W. W. Chin, and P. A. Todd, On the use, usefulness, and ease of use of Structural Equation Modeling in MIS research: A note of caution, MIS Quarterly 19(2) 237-246 (1995).

[32] W. W. Chin, W. D. Salisbury, A. W. Pearson, and M. J. Stollak, Perceived cohesion in small groups: Adapting 
and testing the perceived cohesion scale in a small-group setting, Small Group Research 30(6) 751-766 (1999).

[33] G. A. Churchill, A paradigm for developing better measures of marketing constructs, Journal of Marketing Research 16 64-73 (1979).

[34] C. Clases, R. Bachmann, and T. Wehner, Studying trust in virtual organizations, International Studies of Management and Organization 33(3) 7-27 (2003).

[35] R. L. Daft, and R. H. Lengel, Organizational information requirements, media richness and structural design, Management Science 32(5) 554-571 (1986).

[36] D. R. Deeter-Schmelz, K. N. Kennedy, and R. P. Ramsey, Enriching our understanding of student team effectiveness, Journal of Marketing Education 24(2) 114-124 (2002).

[37] J. E. Driskell, and P. H. Radtke, Virtual teams: Effects of technological mediation on team performance, Group Dynamics: Theory, Research and Practice 7(4) 297-323 (2003).

[38] D. K. Dufner, O. Kwon, Y. T. Park, and Q. Peng, Q. Asynchronous team support: Perceptions of the group problem solving process when using a cybercollaboratory. Paper presented at the Proceeding of the 35th Hawaii, (2002).

[39] H. K. Edwards, and V. Sridhar, Analysis of software requirements engineering exercises in a global virtual team setup, Journal of Global Information Management 13(2) 21-41 (2005).

[40] M. Egger, S. G. Davey, and M. Schneider, Systematic reviews of observational studies. In M. Egger, S. G. Davey and D. Altman (Eds.), Systematic Reviews in Health Care: Meta-analysis in context (pp. 211-227). (London: BMJ Books 2001).

[41] F. Erdem, and F. Ozen, Cognitive and affective dimensions of trust in developing team performance, Team Performance Management 9(5/6) 131-135 (2003).

[42] M. M. Espinoza, Assessing the cross-cultural applicability of a service quality measure: a comparative study between Quebec and Peru, International Journal of Service Industry Management 10 449-468 (1999).

[43] J. L. Fleiss, Statistical Methods for Rates and Proportions, 2nd ed. (John Wiley New York 1981).

[44] C. Fornell and D. F. Larcker, Evaluating structural equation models with unobservable variables and measurement error, Journal of Marketing Research (18 39-50 1981). 
[45] J. Galegher, and R. E. Kraut, Computer-mediated communication for intellectual teamwork: An experiment in group writing, Information System Research 5(2) 110-138 (1994).

[46] F. Gil, R. Rico, C. M. Alcover, and A Barrasa, Change-oriented leadership, satisfaction and performance in work groups, Journal of Managerial Psychology 20(3/4) 312-328 (2005).

[47] C. Gillam, and C. Oppenheim, Review articles: Reviewing the impact of virtual teams in the information age, Journal of Information Science 32(2) 160-175 (2006).

[48] S. G. Green, and T. D. Taber, The effects of three social decision schemes on decision group process, Organizational Behaviour and Human Performance 25 97-106 (1980).

[49] P. S. Greenberga, R. H. Greenbergb, and Y. L. Antonucci, Creating and sustaining trust in virtual teams, Business Horizons 50(4) 325-333 (2007).

[50] J. F. Hair, R. E. Anderson, R. L. Tatham, and W. C. Black, Multivariate data analysis (5th ed.). (New York: Prentice Hall 1998).

[51] D. A. Harrison, K. H. Price, and M. P. Bell, Beyond relational demography: time and the effects of surfaceand deep-level diversity on work group cohesion, Academy of management journal 41(1) 96-107 (1998).

[52] L. V. Hedges, and I. Olkin, (1985). Statistical Methods for Meta-Analysis. (Orlando Academic Press 1985).

[53] A. B. Hollingshead, Communication, learning, and retrieval in transactive memory systems, Journal of Experimental Social Psychology 34(5) 423-442 (1998).

[54] B. V. D. Hooff, and J. A. D. Ridder, Knowledge sharing in context: the influence of organizational commitment, communication climate and CMC use on knowledge sharing, Journal of Knowledge Management 8(6) 117-130 (2004).

[55] T. J. Hostager, S. W. Lester, K. J. Rcady, and M. Bergmann, Matching facilitator style and agenda structure in group support systems: Effects on participant satisfaction and group output quality, Information Resources Management Journal 16(2) 56-72 (2003).

[56] J. E. Hunter, and F. L. Schmidt, Methods of Meta-Analysis: Correcting error and bias in research findings. (Newbury Park: Sage Publications 1990).

[57] M. I. Hwang, The Use of Meta-analysis in MIS Research: Promises and Problems, The Data Base for Advances in Information Systems 27(3) 695-706 (1996). 
[58] B. D. Janz, J. C. Wetherbe, G. B. Davis, and R. A. Noe, Reengineering the systems development process: The link between autonomous team and business process outcomes, Journal of Management Information Systems 14(1) (1997).

[59] S. L. Jarvenpaa, and B. Ives, The global network organization of the future, Journal of Management Information Systems 10(4) 25-58 (1994).

[60] S. L. Jarvenpaa, T. R. Shaw, and D. S. Staples, Toward Contextualised Theories of Trust: The Role of Trust in Global Virtual Teams, Information Systems Research 15(3) 250-267 (2004).

[61] S. L. Jarvenpaa, and D. E. Leidner, Communication and Trust in Global Virtual Teams, Organization Science 10(6) 791-815 (1999).

[62] J. J. Jiang, E. Chen, and G. Klein, The importance of building a foundation for user involvement in information system projects, Project Management Journal 33(1) 20-26 (2002).

[63] C. Johansson, Y. Dittrich, and A. Juustila, (1999). Software engineering across boundaries: Student project in distributed collaboration, IEEE Transactions on Professional Communication 42(4) 286-296 (1999).

[64] K. G. Jöreskog, and D. Sörbom, LISREL 8: Structural Equation Modeling with the SIMPLIS Command Language, (Scientific Software International Chicago, IL 1993).

[65] C. M. Judd, E. R. Smith, and L. H. Kidder, Research methods in social relations (6th ed.). Fort Worth: Harcourt Brace Jovanovich, (1991).

[66] S. S. Kahai, and R. B. Cooper, The effect of computer-mediated communication on agreement and acceptance, Journal of Management Information Systems 16(1) 165-188 (1999).

[67] P. Kaiser, W. Tullar, and D. McKowen, Student Team Projects by Internet, Business Communication Quarterly 63(4) 75-82 (2000).

[68] P. Kanawattanachai, and Y. Yoo, The impact of knowledge coordination on virtual team performance over time, MIS Quarterly 31(4) 783-808 (2007).

[69] K. J. Kettinger, and V. Grover, The use of computer-mediated communication in an interorganizational context, Decision Science 28(3) 513-555 (1997).

[70] B. L. Kirkman, B. Rosen, P. E. Tesluk, and C. B. Gibson, The impact of team empowerment on virtual team performance: The moderating role of face-to-face interaction, Academy of Management Journal 47(2) 
175-192 (2004).

[71] D. Kitchen, and D. McDougall, Collaborative Learning on the Internet, Journal of Educational Technology Systems 27(3) 245-258 (1999).

[72] N. Kock, and G. Lynn, The E-Collaboration paradox: A study of 290 new product development teams. Paper presented at the IRMA International Conference (2005).

[73] R. Kraut, C. Steinfield, A. P.Chan, B. Butler, B., and A. Hoag, Coordination and Virtualization: The role of electronic networks and personal relationships, Organization Science 10(6) 722-740 (1999).

[74] T. R. Kurtzberg, C. E. Naquin, and L. Y. Belkin, Electronic performance appraisals: The effects of e-mail communication on peer ratings in actual and simulated environments, Organizational Behavior and Human Decision Processes 98(2) 216-226 (2005).

[75] X. Li, J. S. Valacich, and T. J. Hess, Predicting user trust in information systems: A Comparison of competing trust. Paper presented at the International Conference on System Sciences, Hawaii, (2004).

[76] M. Lind, The Gender Impact of Temporary Virtual Work Groups, IEEE Transactions of Professional Communication, 42(4) 276-285 (1999).

[77] J. Lipnack, and J. Stamps, Virtual teams (Second ed.). (United States: John Wiley and Sons 2000).

[78] A. J. Lott, and B. D. Lott, Group cohesiveness as interpersonal attraction: A review of relationships with antecedent and consequent variables, Psychological Bulletin 64 259-309 (1965).

[79] M. Lu, M. B. Watson-Manheim, K. M. Chudoba, and E. Wynn, Virtuality and Team Performance: Understanding the Impact of Variety of Practices, Journal of Global Information Technology Management 9(1), 4-23, (2006).

[80] Y. Luo, Building trust in cross-cultural coordinations: Toward a contingency perspective, Journal of Management 28(5) 669-694 (2002).

[81] J. S. Lurey, and M. S. Raisinghani, An empirical study of best practices in virtual teams, Information and Management 38(8) 523-544 (2001).

[82] L. L. Martins, L., Gilson, and M. T. Maynard, Virtual Teams: What Do We Know and Where Do We Go From Here?, Journal of Management 30(6) 805-835 (2004).

[83] A. P. Massey, M. Montoya-Weiss, and Y. T. C. Hung, Synchronizing pace in asynchronous global virtual 
project teams. Paper presented at the Proceedings of the 35th Hawaii International Conference on System Sciences, (2002).

[84] A. V. Matveev, and P. E. Nelson, Cross cultural communication competence and multicultural team performance-perceptions of American and Russian managers, International Journal of Cross Cultural Management 4(2) 253-270 (2004).

[85] R. C. Mayer, J. H. Davis, and F. D. Schoorman, An integration model of organizational trust, Academy of Management Review 20(3) 709-730 (1995).

[86] M. L. Maznevski, and K. M. Chudoba, Bridging space over time: Global virtual team dynamics and effectiveness, Organization Science 11(5) 473-492 (2000).

[87] J. E. McGrath, Groups: Interaction and performance. (Englewood Cliffs Prentice Hall 1984).

[88] J. E. McGrath, Time, interaction, and performance (TIP): A Theory of groups, Small Group Research 22(2) 147-174 (1991).

[89] S. Meyerson, K. E. Weick, and R. M. Kramer, "Swift trust and temporary groups", in Kramer, R.M., Tyler, T.R. (Eds), Trust in Organizations: Frontiers of Theory and Research, (Sage Publications Thousand Oaks CA 1996).

[90] M. M. Montoya-Weiss, A. P. Massey, and M. Song, Getting it together: Temporal coordination and conflict management in global virtual teams, Academy of Management Journal 44(6) 1251-1262 (2001).

[91] S. A. Morris, T. Marshall, and R. KellyRainer, Impact of user satisfaction and trust on virtual team members, Information Resources Management Journal 15(2) 22-30 (2002).

[92] S. Newell, G. David, and D. Chand, Exploring trust among globally distributed work teams. Paper presented at the The 40th Hawaii International Conference on System Sciences, Hawaii, (2007).

[93] R. J. Ocker, The mediating effect of group development on satisfaction in a virtual and mixed-mode environment. Paper presented at the Proceedings of the 35th Hawaii International Conference on System Sciences, (2002).

[94] B. A. Olaniran, A model of group satisfaction in computer-mediated communication and face-to-face meetings, Behaviour and Information Technology 15(1) 24-36 (1996).

[95] S. Paul, P. Seetharaman, I. Samarah, and P. P. Mykytyn, (2004). Impact of heterogeneity and collaborative 
conflict management style on the performance of synchronous global virtual teams, Information and Management 41 303-321 (2004).

[96] D. J. Pauleen, An inductively derived model of leader-initiated relationship building with virtual teams members, Journal of Management Information Systems 20(3) 227-256 (2003).

[97] P. A. Pavlou, Institution-based trust in interorganizational exchange relationships: the role of on line B2B marketplaces on trust formation, Journal of strategic information systems 11 215-243 (2002).

[98] G. Piccoli, A. Powell, and B. Ives, Virtual teams: Team control structure, work processes, and team effectiveness, Information Technology and People 17(4) 359-379 (2004).

[99] A. Pinsonneault, and O. Caya, Virtual Teams: What We Know and What We Don't Know, International Journal of e-Collaboration 1(3) 1-16 (2005).

[100] R. E. Potter, and P. A. Balthazard, Understanding human interaction and performance in the virtual team, Journal of Information Technology Theory and Application 4(1) 1-23 (2002).

[101] A. Powell, J. Galvin, and G. Piccoli, Antecedents to team member commitment from near and far: A comparison between collocated and virtual teams, Information Technology and People 19(4) 299-322 (2006).

[102] A. Powell, G. Piccoli, and B. Ives, Virtual teams: A review of current literature and directions for future research, Database for Advances in Information Systems 35(1) 6-36 (2004).

[103] J. M. Purdy, and P. Nye, The impact of communication media on negotiation outcomes, The International Journal of Conflict Management 11(2) 162-187 (2000).

[104] D. Robey, H. M. Khoo, and C. Powers, Situated learning in cross-functional virtual teams, IEEE Transactions on Professional Communications 43(1) 51-66 (2000).

[105] B. Rosen, S. Furst, and R. Blackburn, Training for virtual teams: An investigation of current practices and future needs, Human Resource Management 45(2) 229-247 (2006).

[106] D. Ross, and B. B. Blasch, Development of a wearable computer orientation system, IEEE Personal and Ubiquitous Computing 6 49-63 (2002).

[107] W. D. Salisbury, T. A. Carte, and L. Chidambaram, Cohesion in virtual teams: validating the perceived cohesion scale in a distributed setting, ACM SIGMIS Database 37(2/3) 147-155 (2006).

[108] M. Sarbaugh-Thompson, and M. S. Feldman, Electronic mail and organizational communication: Does saying "Hi" really matter? Organization Science 9(6) 685-698 (1998). 
[109] L. D. Sargent, and C. Sue-Chan, Does diversity affect group efficacy? the intervening role of cohesion and task interdependence, Small Group Research 32(4) 426-450 (2001).

[110] S. Sarker, F.Lau, F., and S. Sahay, Using An Adapted Grounded Theory Approach for Inductive Theory Building About Virtual Team Development, Database for Advances in Information Systems 32(1) 38-56 (2001).

[111] S. Sawyer, and P. J. Guinan, Software development: Processes and performance, IBM Systems Journal 37(4) 552-568 (1998).

[112] J. Siegel, V. Dubrovsky, S. Kiesler, and T. W. McGuire, Group processes in computer-mediated communication, Organizational Behavior and Human Decision Processes 37(2) 157-187 (1986).

[113] C. M. Solomon, Managing virtual teams, Workforce 80(6) 60-64 (2001).

[114] D. S. Staples, J. S. Hulland, and C. A. Higgins, A self-efficacy theory explanation for the management of remote workers in virtual organizations, Organization Science 10(6) 758-776 (1999).

[115] S. G. Straus, Getting a clue: The effects of communication media and information distribution on participation and performance in computer-mediated and face-to-face groups, Small Group Research 27(1) 115-142 (1996).

[116] S. G. Straus, Technology, group process, and group outcomes: Testing the connections in computer-mediated and face-to-face groups, Human-Computer Interaction 12 227-266 (1997).

[117] S. G. Straus, J. A. Miles, and L. L. Levesque, The effects of videoconference, telephone, and face-to-face media on interviewer and applicant judgments in employment interviews, Journal of management 27(3) 363-381 (2001).

[118] S. W. Sussman, and L. Sproull, Straight talk: Delivering bad news through electronic communication, Information Systems Research 10(2) 150-166 (1999).

[119] K. Swan, Virtual interaction: Design factors affecting student satisfaction and perceived learning in asynchronous online courses, Distance Education 22(2) 306-331 (2001).

[120] D. Te’eni, A Cognitive-Affective Model of Organizational Communication For Designing IT, MIS Quarterly, 25(2) 251-312 (2001).

[121] L. C. Tidwell, and J. B. Walther, Computer-mediated communication effects on disclosure, impression and 
interpersonal evaluations: Getting to know one another a bit at a time, Human Communication Research 28(3) 317-348 (2002).

[122] J. Tillquist, Participation on electronic bulletin board systems: An empirical analysis of work, Journal of Management Information System, 13(1) 107-126 (1996).

[123] K. L. Tyran, C. K. Tyran, and M. Shepherd, Exploring Emerging Leadership in Virutal Teams, In Gibson, C. B. and Cohen, S. (Eds.), Virtual Teams That Work: Creating Conditions for Virtual Teams Effectiveness, (San Francisco CA 193-195 2003).

[124] J. S. Valacich, and S. Sarker, Computer-mediated and face-to-face groups: Who makes riskier decisions? Paper presented at the Proceedings of the 35th Hawaii International Conference on System Sciences, (2002).

[125] J. B. Walther, Interpersonal effects in computer-mediated interaction: A relational perspective. Communication Research 19(1) 52-90 (1992).

[126] C. C. Ward, and T. J. G. Tracey, Relation of shyness with aspects of online relationship involvement, Journal of Social and Personal Relationships 21(5) 611-623 (2004).

[127] M. E. Warkentin, L. Sayeed, and R. Hightower, Virtual teams versus face-to-face teams: An exploratory study of a web-based conference system, Decision Science 28(4) 975-996 (1997).

[128] Y. Yoo, and M. Alavi, Media and group cohesion: Relative influences on social presence, task participation, and group consensus, MIS Quarterly 25(3) 371-390 (2001).

[129] Y. Yoo, and P. Kanawattanachai, Developments of transactive memory systems and collective mind in virtual teams, International Journal of Organizational Analysis 9(2) 187-208 (2001).

[130] R. Zolin, P. J. Hinds, R. Fruchter, and R. E. Levitt, Interpersonal trust in cross-functional, geographically distributed work: A longitudinal study, Information and Organization 14 1-26 (2004).

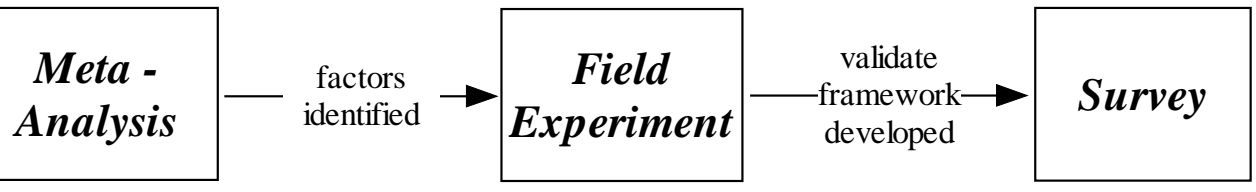


Figure 1: The research process

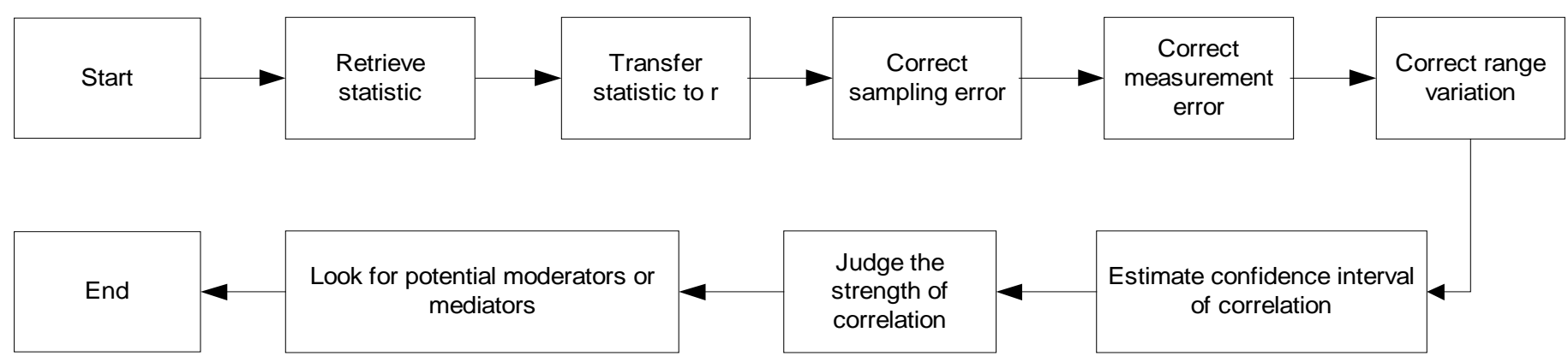

Figure 2. The Hunter and Schmidt's method of meta-analysis (Source: [56])

\begin{tabular}{|c|c|c|c|}
\hline Constructs & Measurement Items & Sources & $\begin{array}{l}\text { Reliability } \\
\text { (alpha) }\end{array}$ \\
\hline $\begin{array}{l}\text { Relationship } \\
\text { building }\end{array}$ & $\begin{array}{l}\text { - My group members relied on each other and consulted each } \\
\text { other when they needed support } \\
\text { - My group members experienced a sense of shared goals and } \\
\text { objectives } \\
\text { - Knowledge and information sharing was understood to be a } \\
\text { group norm within my group } \\
\text { - My group was a very cohesive unit }\end{array}$ & [81] & 0.92 \\
\hline Cohesion & $\begin{array}{l}\text { - My group members went their own way rather than get together } \\
\text { as a group during the period of the case study } \\
\text { - I feel my group members rarely worked together } \\
\text { - My group members spent time together outside the case study } \\
\text { work }\end{array}$ & {$[26]$} & 0.78 \\
\hline Communication & $\begin{array}{l}\text { - I am as interested in building a good relationship as in } \\
\text { completing the case study } \\
\text { - I wanted to stick to the main purpose of the discussion } \\
\text { - I think our group members had effective communication }\end{array}$ & {$[21]$} & 0.75 \\
\hline Coordination & $\begin{array}{l}\text { - I tried to bring all our concerns out in the open so that the issues } \\
\text { could be resolved in the best possible way } \\
\text { - I tried to work with my group members to find solutions that } \\
\text { satisfied our expectations } \\
\text { - I exchanged useful information with my group members to solve }\end{array}$ & $\begin{array}{l}\text { Montoya-Weiss } \\
\text { et al. (2001) }\end{array}$ & 0.85 \\
\hline
\end{tabular}




\begin{tabular}{|c|c|c|c|}
\hline & $\begin{array}{l}\text { the problem together } \\
\text { - I tried to investigate an issue with my group members to find a } \\
\text { solution acceptable to us }\end{array}$ & & \\
\hline Performance & $\begin{array}{l}\text { - } \quad \text { My group worked efficiently } \\
\text { - } \quad \text { My group met our objectives } \\
\text { - My group generally worked on schedule }\end{array}$ & {$[81]$} & 0.89 \\
\hline Satisfaction & $\begin{array}{l}\text { - Team members were satisfied with the group's ability } \\
\text { - Team members were satisfied with the commitment of the group } \\
\text { - Team members were confident in the group }\end{array}$ & {$\left[\begin{array}{l}{[30],} \\
{[48]}\end{array}\right.$} & 0.86 \\
\hline
\end{tabular}

Table 1. Measurement items and scale reliabilities of variables

\begin{tabular}{|l|l||l|l|}
\hline Relationship & Point estimate & Relationship & Point estimate \\
\hline CR-PF & 0.53 & CH-ST & 0.57 \\
\hline CR-ST & 0.39 & RB-PF & 0.21 \\
\hline CM-PF & 0.32 & RB-ST & 0.36 \\
\hline CH-PF & 0.36 & TR-PF & $\mathbf{0 . 2 9}$ \\
\hline
\end{tabular}

RB-Relationship Building; CH-Cohesion; TR-Trust; CM-Communication; CR-Coordination; PF-Performance; ST-Satisfaction

Table 2. Eight significant relationships

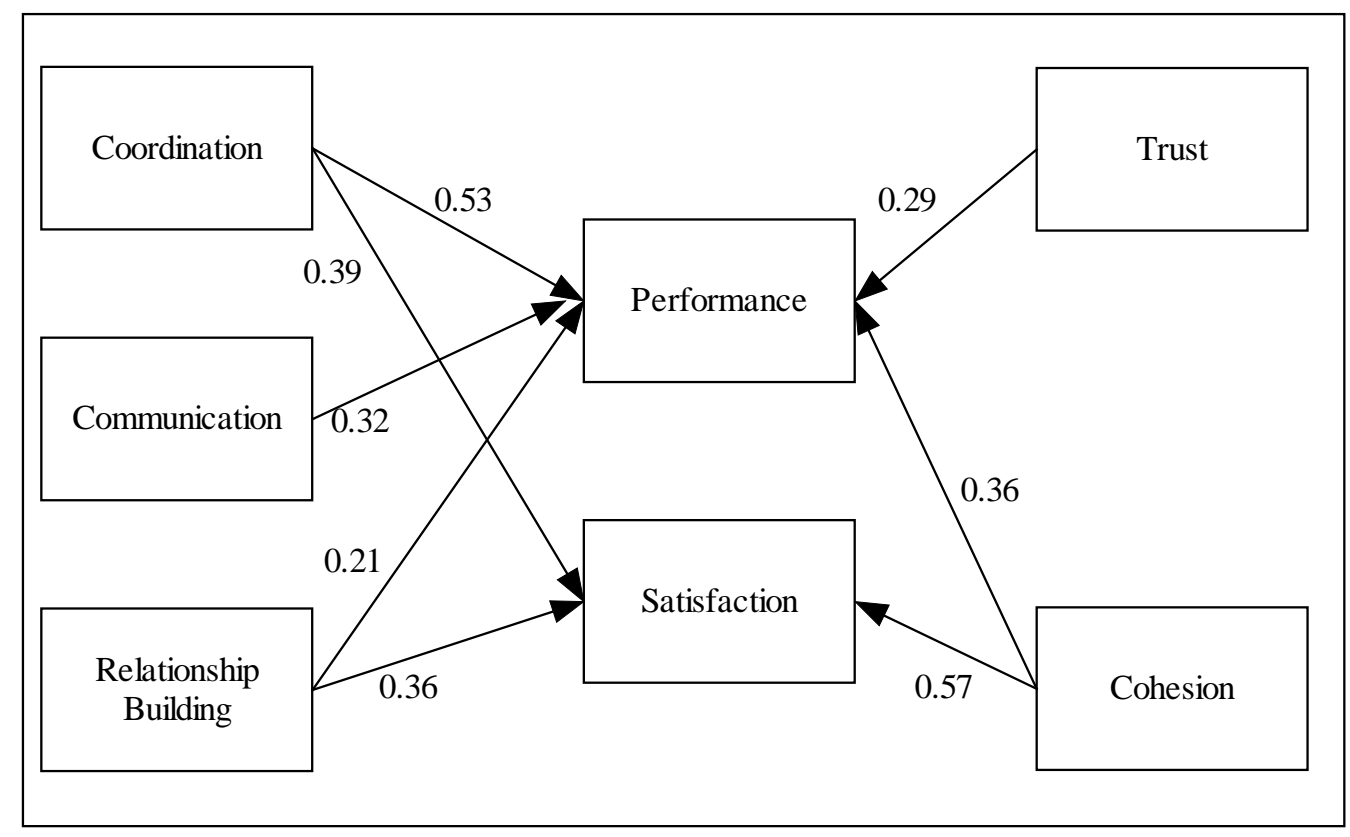

Figure 3. The preliminary model for evaluating the effectiveness of virtual teams 


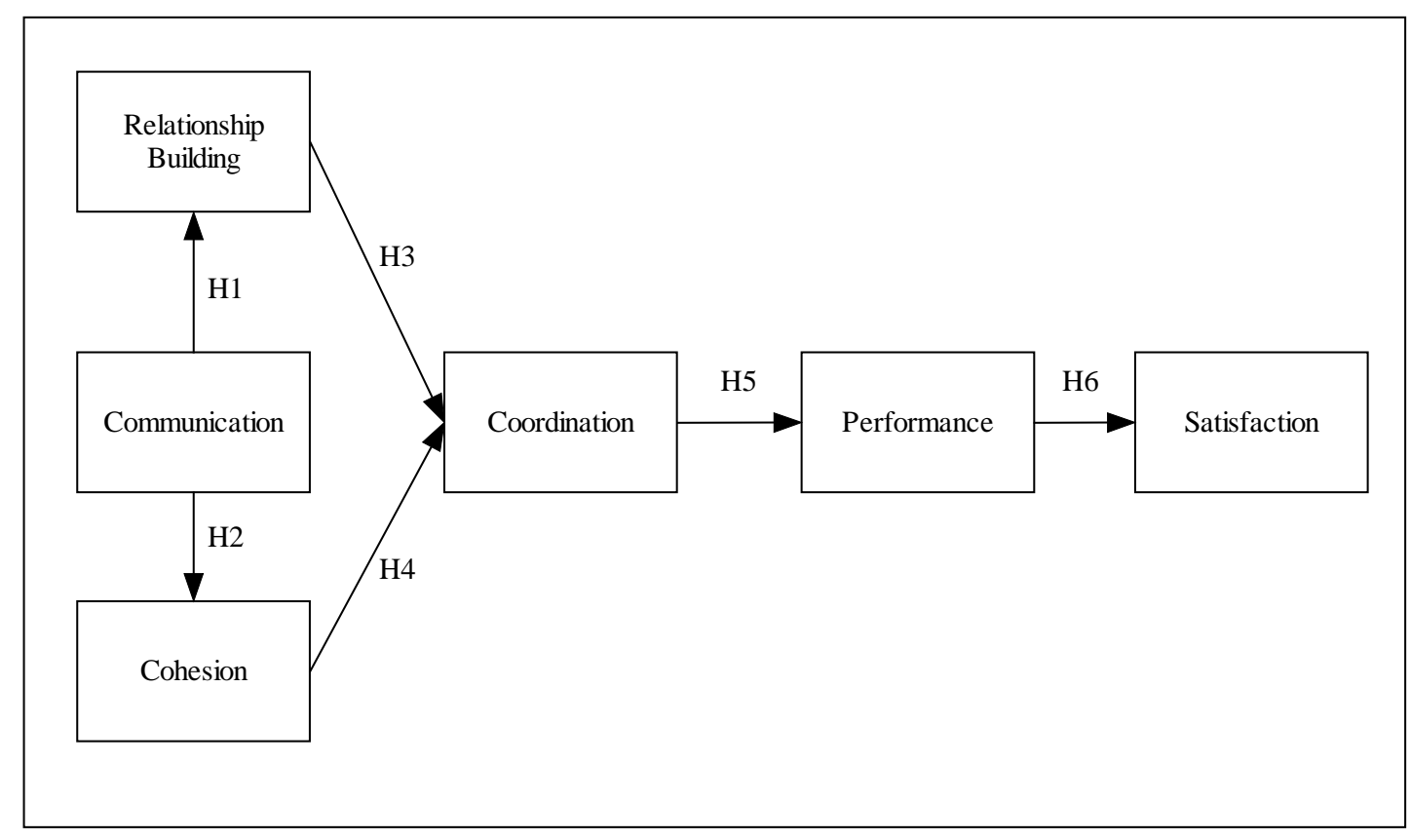

Figure 4. An integrated model of virtual team effectiveness

\begin{tabular}{lllllllllll}
\hline & Mean & S.D. & C1 & C2 & C3 & C4 & C5 & C6 & Alpha $^{\mathrm{a}}$ & CR $^{\mathrm{b}}$ \\
C1 Relationship building & 4.60 & 1.50 & $.76^{\mathrm{c}}$ & & & & & & .92 & .93 \\
C2 Cohesion & 4.38 & 1.63 & .72 & .63 & & & & & .78 & .78 \\
C3 Coordination & 5.26 & 1.02 & .38 & .36 & .56 & & & & .85 & .84 \\
C4 Performance & 4.94 & 1.57 & .80 & .76 & .31 & .76 & & & .89 & .90 \\
C5 Satisfaction & 5.36 & 1.18 & .52 & .41 & .19 & .58 & .73 & .86 & .87 \\
C6 Communication & 4.06 & 1.09 & .94 & .76 & .37 & .79 & .42 & .51 & .75 & .74 \\
\hline
\end{tabular}

${ }^{+} \mathrm{p}<.10 ;{ }^{*} \mathrm{p}<.05 ;{ }^{* *} \mathrm{p}<.01 ;{ }^{* * *} \mathrm{p}<.001$

${ }^{a}$ Internal Consistency Reliability (Cronbach’s coefficient alpha).

${ }^{\mathrm{b}}$ Composite Reliability [44].

${ }^{\mathrm{c}}$ The diagonal (in italics) shows the average variance extracted [44] for each construct.

Table 3. Covariance Matrix for Constructs 


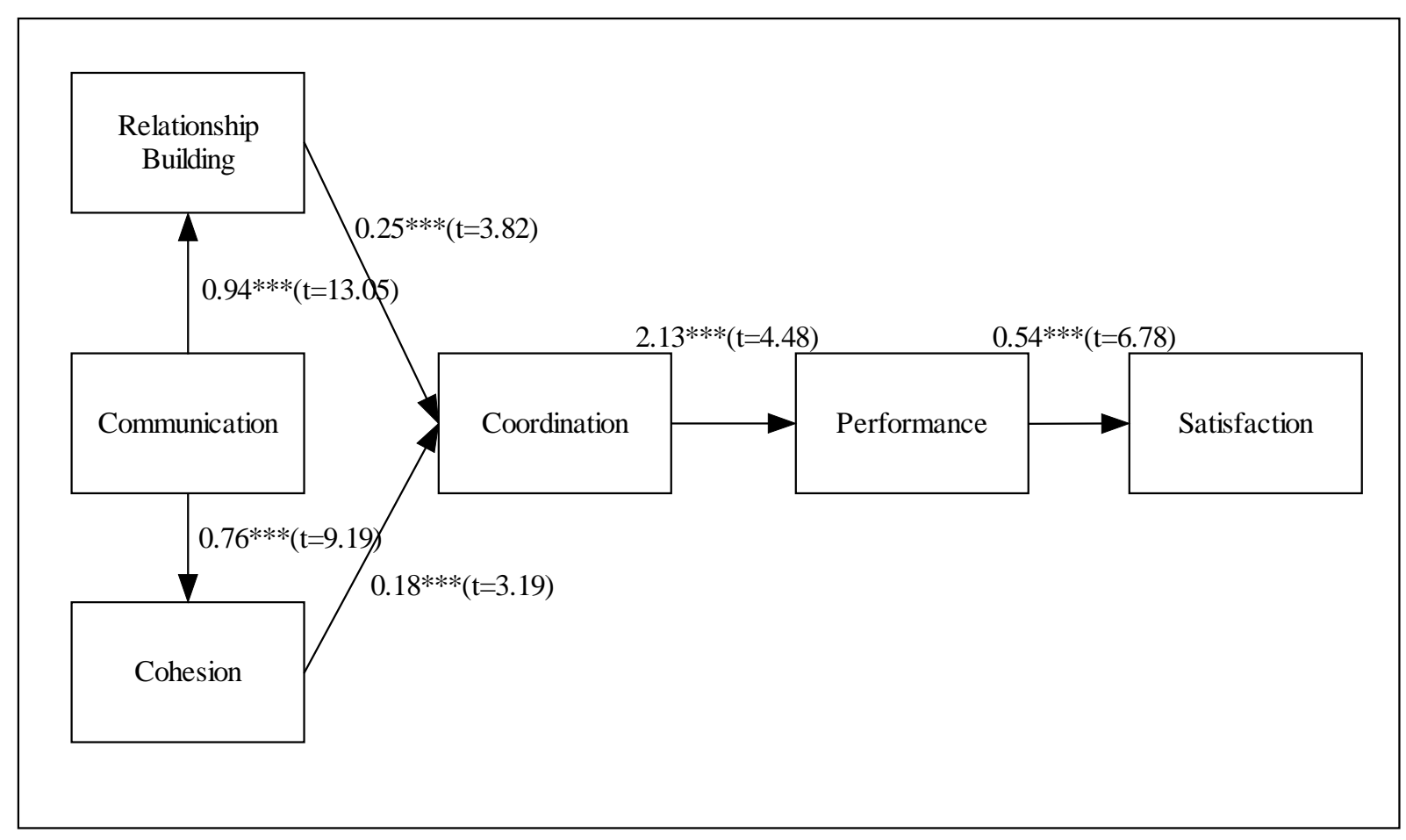

$\chi^{2}=230.07, \mathrm{p}<0.001, \mathrm{df}=133, \mathrm{RMSEA}=0.06, \mathrm{CFI}=0.98, \mathrm{NFI}=0.96, \mathrm{GFI}=0.89, \mathrm{AGFI}=0.84$

All solid line path coefficients are significant at $\mathrm{p}<0.001^{* * *}$.

Figure 5. Structural Equation Model Results (H1 through H6)

\begin{tabular}{|l|l|l|}
\hline Items & Hypotheses & Supported? \\
\hline H1 & Communication is positively related to relationship building. & Yes \\
\hline H2 & Communication is positively related to cohesion. & Yes \\
\hline H3 & Relationship building is positively related to coordination. & Yes \\
\hline H4 & Cohesion is positively related to coordination. & Yes \\
\hline H5 & Coordination is positively related to performance. & Yes \\
\hline H6 & Performance is positively related to satisfaction. & Yes \\
\hline
\end{tabular}

Table 4. The six proposed research hypotheses

\begin{tabular}{|l|l|l|l|}
\hline & & Performance & Satisfaction \\
\hline Communication & Direct effect & --- & --- \\
& Indirect effect & 0.79 & 0.40 \\
& Total effect & 0.79 & 0.40 \\
\hline Relationship & Direct effect & --- & --- \\
building & Indirect effect & 0.58 & 0.31 \\
& Total & 0.58 & 0.31 \\
\hline Cohesion & Direct effect & --- & --- \\
& Indirect effect & 0.38 & 0.19 \\
& Total & 0.38 & 0.19 \\
\hline Coordination & Direct effect & 2.13 & --- \\
& Indirect effect & --- & 1.24 \\
\hline
\end{tabular}


Table 5. Total/ direct/ indirect effects

\section{Appendices}

Appendix 1. The Collection of Correlation of Studies

\begin{tabular}{|c|c|c|c|c|c|c|}
\hline \multirow{2}{*}{\begin{tabular}{|l} 
First Author \\
{$[1]$}
\end{tabular}} & \multirow{2}{*}{\begin{tabular}{|l|} 
Year \\
1997 \\
\end{tabular}} & \multirow{2}{*}{\begin{tabular}{|l|} 
Sample \\
102 \\
\end{tabular}} & \multicolumn{4}{|l|}{ Correlation (r) } \\
\hline & & & CM-ST:0.14 & CM-PF:0.17 & & \\
\hline [2] & 1997 & 73 & TC-PF:0.14 & & & \\
\hline [9] & 2001 & 117 & TR-PF:0.62 & CR-TR:0.70 & CR-PF:0.47 & \\
\hline$[10]$ & 2003 & 68 & TR-PF:0.33 & RB-TR:-0.23 & & \\
\hline \multirow[t]{2}{*}{ [12] } & \multirow[t]{2}{*}{2004} & \multirow[t]{2}{*}{248} & CR-PF:0.69 & CH-PF:0.45 & CR-CH:0.23 & CH-ST:0.62 \\
\hline & & & CR-ST:0.19 & CH-PF:0.24 & & \\
\hline \multirow[t]{2}{*}{ [13] } & \multirow[t]{2}{*}{2001} & \multirow[t]{2}{*}{1048} & CR-PF:0.30 & DS-PF:0.46 & RB-PF:0.29 & TC-PF:0.54 \\
\hline & & & CM-PF:0.46 & & & \\
\hline [14] & 2005 & 287 & CR-PF:0.16 & CR-PF:0.24 & & \\
\hline [24] & 2005 & 124 & CR-ST:0.49 & & & \\
\hline \multirow[t]{3}{*}{ [25] } & \multirow[t]{3}{*}{2000} & \multirow[t]{3}{*}{120} & CR-PF:0.67 & CH-ST:0.31 & CM-CR:0.62 & TC-ST:-0.07 \\
\hline & & & CR-PF:0.69 & CH-PF:0.36 & CM-CH:0.49 & TR-ST:0.45 \\
\hline & & & CR-ST:0.49 & CH-PF:0.15 & & \\
\hline [28] & 2001 & 25 & CH-PF:0.03 & CR-PF:0.68 & & \\
\hline [28] & 2001 & 22 & CR-PF:0.77 & & & \\
\hline \multirow[t]{2}{*}{ [39] } & \multirow[t]{2}{*}{2005} & \multirow[t]{2}{*}{201} & TC-PF:0.05 & TT-PF:0.08 & TR-PF:0.17 & CU-PF:-0.14 \\
\hline & & & DS-PF:-0.02 & & & \\
\hline \begin{tabular}{|l}
$46]$ \\
\end{tabular} & 2005 & 268 & CH-PF:0.54 & CH-ST:0.84 & DS-PF:0.26 & ST-PF:0.55 \\
\hline [51] & 1998 & 443 & CH-ST:0.35 & & & \\
\hline [54] & 2004 & 417 & CM-PF:0.03 & CR-PF:0.14 & & \\
\hline \begin{tabular}{|l}
$55]$ \\
\end{tabular} & 2003 & 550 & DS-PF:0.02 & & & \\
\hline \begin{tabular}{|l}
$60]$ \\
\end{tabular} & 2004 & 136 & CH-ST:0.71 & CH-PF:0.71 & ST-PF:0.70 & \\
\hline$[62]$ & 2002 & 186 & RB-PF:-0.20 & & & \\
\hline$[66]$ & 1999 & 94 & CR-ST:0.29 & RB-ST:0.28 & CM-CR:-0.37 & \\
\hline [69] & 1997 & 613 & DS-RB:-0.03 & CR-RB:0.12 & DS-CR:0.01 & \\
\hline \multirow[t]{3}{*}{ [70] } & \multirow[t]{3}{*}{2004} & \multirow[t]{3}{*}{280} & DS-PF: -0.02 & DS-CR:-0.06 & RB-TT:-0.17 & CR-RB:0.22 \\
\hline & & & DS-ST:-0.02 & DS-RB:0.05 & TT-PF:-0.20 & CR-PF:0.39 \\
\hline & & & DS-TT:-0.28 & CR-TT:0.19 & TT-SF:-0.10 & CR-ST:0.44 \\
\hline \begin{tabular}{|l} 
[73] \\
\end{tabular} & 1999 & 250 & RB-PF:0.15 & TC-PF:-0.17 & TC-ST:0.07 & RB-ST:0.20 \\
\hline [79] & 2006 & 787 & CM-PF:-0.05 & CR-PF:-0.03 & RB-PF:0.02 & TR-PF:0.04 \\
\hline$[80]$ & 2002 & 255 & TR-PF:0.25 & CU-PF:-0.11 & CU-TR:-0.19 & \\
\hline \multirow[t]{2}{*}{ [81] } & \multirow[t]{2}{*}{2001} & \multirow[t]{2}{*}{67} & PF-ST:0.73 & $R B-P F: 0.62$ & RB-ST:0.64 & CM-PF:0.48 \\
\hline & & & CM-ST:0.37 & DS-ST:0.36 & TC-PF:0.26 & TC-ST:0.42 \\
\hline [90] & 2001 & 175 & DS-PF:-0.32 & & & \\
\hline [91] & 2002 & 158 & DS-ST:-0.02 & DS-TR:-0.06 & DS-TC:0.29 & \\
\hline [93] & 2002 & 83 & CH-ST:0.35 & CR-ST:0.32 & & \\
\hline [94] & 1996 & 116 & TC-CR:0.49 & TC-ST:-0.19 & CR-ST:0.05 & \\
\hline [95] & 2004 & 63 & CR-PF:0.40 & CR-ST:0.80 & & \\
\hline [97] & 2002 & 102 & RB-ST:0.58 & CR-RB:-0.47 & & \\
\hline
\end{tabular}




\begin{tabular}{|c|c|c|c|c|c|c|}
\hline \multirow[t]{2}{*}[98]{} & \multirow[t]{2}{*}{2004} & \multirow[t]{2}{*}{201} & DS-CR:0.07 & CR-PF:0.07 & CM-PF:0.23 & DS-PF:0.04 \\
\hline & & & DS-CM:0.12 & CR-ST:0.29 & CM-ST:0.23 & DS-ST:-0.14 \\
\hline$[100]$ & 2002 & 272 & \multicolumn{4}{|l|}{ CH-PF:0.24 } \\
\hline$[101]$ & 2006 & 72 & \multicolumn{4}{|l|}{ TT-TR:0.83 } \\
\hline$[103]$ & 2000 & 73 & \multicolumn{4}{|l|}{ CR-ST:0.31 } \\
\hline$[105]$ & 2006 & 440 & \multicolumn{4}{|l|}{ TA-PF:0.90 } \\
\hline [109] & 2001 & 42 & \multicolumn{4}{|l|}{ CH-PF:0.47 } \\
\hline [112] & 1986 & 42(exp1) & CR-PF:0.84 & $R B-P F: 0.11$ & & \\
\hline$[112]$ & 1986 & 24(exp2) & CR-PF:0.35 & $R B-P F: 0.25$ & & \\
\hline [112] & 1986 & $36(\exp 3)$ & CR-PF:0.97 & CH-PF:0.01 & RB-PF:0.08 & \\
\hline$[114]$ & 1999 & 631 & TC-PF:0.27 & TC-ST:0.22 & TR-TC:0.20 & \\
\hline [68] & 2007 & 146 & \multicolumn{4}{|l|}{ CR-TR:0.61 } \\
\hline$[116]$ & 1997 & 216 & CM-PF:0.47 & CM-PF:0.58 & $C M-P F: 0.64$ & \\
\hline$[118]$ & 1999 & 117 & CM-ST:0.39 & & & \\
\hline [119] & 2001 & 1406 & CR-ST:0.44 & DS-ST:0.33 & CM-ST:0.76 & \\
\hline [122] & 1996 & 73 & CR-RB:0.21 & & & \\
\hline$[127]$ & 1997 & 72 & CM-PF:0.01 & TC-PF:0.46 & TC-CH:0.60 & \\
\hline$[128]$ & 2001 & 135 & CH-RB:0.75 & CH-CR:0.32 & CR-PF:0.70 & RB-PF:0.07 \\
\hline [129] & 2001 & 146 & $R B-P F: 0.36$ & $R B-P F: 0.45$ & & \\
\hline$[130]$ & 2004 & 216 & CU-TR:0.01 & & & \\
\hline
\end{tabular}

DS: Design; CU: Culture; TC: Technical Expertise; RB: TA: Training; Relationship building; $\mathrm{CH}$ : Cohesion;

TR:Trust; CM: Communication; CM: Coordination; TT: Task-Technology structure fit; ST: Satisfaction; PF: Performance

Appendix 2. Frequency Distribution of Variables’ relationships

\begin{tabular}{|l|c|c|c|c|c|c|c|c|c|c|}
\hline Item & DS-CR & CR-PF & CR-ST & CM-PF & CM-ST & DS-PF & DS-ST & CR-RB & CH-PF & CH-ST \\
\hline Frequency & 3 & 18 & 11 & 10 & 5 & 7 & 5 & 4 & 10 & 6 \\
\hline Item & RB-PF & TC-PF & CM-CR & TC-ST & RB-ST & TR-PF & CR-CH & CM-CH & CR-TT & CU-PF \\
\hline Frequency & 11 & 7 & 2 & 5 & 4 & 5 & 1 & 1 & 1 & 1 \\
\hline \hline Item & CU-TR & DS-TT & DS-RB & DS-TR & DS-TC & DS-CM & RB-TT & TR-ST & TT-PF & TT-SF \\
\hline Frequency & 1 & 1 & 1 & 1 & 1 & 1 & 1 & 1 & 1 & 1 \\
\hline \hline Item & TC-CR & TR-TC & TT-TR & TA-PF & CR-TR & & & & & \\
\hline Frequency & 1 & 1 & 1 & 1 & 1 & & & & & \\
\hline
\end{tabular}

Appendix 3. Meta-analysis of correlation of variables

\begin{tabular}{|c|c|c|c|c|c|c|c|c|c|c|c|}
\hline & \begin{tabular}{|l|} 
Fixed / \\
Random
\end{tabular} & $\mathbf{N}$ & Effect & $\begin{array}{l}95 \% \\
\text { confid } \\
\text { interv } \\
\text { Low }\end{array}$ & $\begin{array}{l}\text { ence } \\
\text { al } \\
\text { High }\end{array}$ & Ntotal & P-Value & $\begin{array}{l}\text { Point } \\
\text { estimate }\end{array}$ & Q-Value & Df(Q) & P-Value(Q) \\
\hline \multirow[t]{2}{*}{ DS-CR } & $\begin{array}{l}\text { Transform } \\
\text { Fixed }\end{array}$ & 3 & 0.00 & -0.06 & 0.06 & 1094 & 0.96 & 0.00 & \multirow{2}{*}{2.03} & \multirow{2}{*}{2} & \multirow{2}{*}{0.36} \\
\hline & $\begin{array}{l}\text { Transform } \\
\text { Random }\end{array}$ & 3 & 0.00 & -0.06 & 0.06 & 1094 & 0.96 & 0.00 & & & \\
\hline \multirow[t]{2}{*}{ CR-PF } & $\begin{array}{l}\text { Transform } \\
\text { Fixed }\end{array}$ & 18 & 0.31 & 0.29 & 0.34 & 4259 & 0.00 & 0.31 & \multirow{2}{*}{453.91} & \multirow{2}{*}{17} & \multirow{2}{*}{0.00} \\
\hline & \begin{tabular}{|l|} 
Transform \\
Random
\end{tabular} & 18 & 0.53 & 0.40 & 0.64 & 4259 & 0.00 & $0.53 * *$ & & & \\
\hline
\end{tabular}




\begin{tabular}{|c|c|c|c|c|c|c|c|c|c|c|c|}
\hline \multirow[t]{2}{*}{ CR-ST } & $\begin{array}{l}\text { Transform } \\
\text { Fixed } \\
\end{array}$ & 11 & 0.40 & 0.37 & 0.43 & 2808 & 0.00 & 0.40 & \multirow{2}{*}{69.45} & \multirow{2}{*}{10} & \multirow{2}{*}{0.00} \\
\hline & \begin{tabular}{|l|} 
Transform \\
Random
\end{tabular} & 11 & 0.39 & 0.28 & 0.49 & 2808 & 0.00 & $0.39 * *$ & & & \\
\hline \multirow[t]{2}{*}{ CM-PF } & $\begin{array}{l}\text { Transform } \\
\text { Fixed }\end{array}$ & 10 & 0.29 & 0.26 & 0.32 & 3342 & 0.00 & 0.29 & \multirow{2}{*}{260.59} & \multirow{2}{*}{9} & \multirow{2}{*}{0.00} \\
\hline & \begin{tabular}{|l|} 
Transform \\
Random
\end{tabular} & 10 & 0.32 & 0.13 & 0.49 & 3342 & 0.00 & $0.32 * *$ & & & \\
\hline \multirow[t]{2}{*}{ CM-ST } & $\begin{array}{l}\text { Transform } \\
\text { Fixed }\end{array}$ & 5 & 0.67 & 0.65 & 0.70 & 1893 & 0.00 & 0.67 & \multirow{2}{*}{190.32} & \multirow{2}{*}{4} & \multirow{2}{*}{0.00} \\
\hline & \begin{tabular}{|l|} 
Transform \\
Random
\end{tabular} & 5 & 0.41 & -0.03 & 0.72 & 1893 & 0.07 & 0.41 & & & \\
\hline \multirow[t]{2}{*}{ DS-PF } & $\begin{array}{l}\text { Transform } \\
\text { Fixed }\end{array}$ & 7 & 0.20 & 0.16 & 0.24 & 2723 & 0.00 & 0.20 & \multirow{2}{*}{184.94} & \multirow{2}{*}{6} & \multirow{2}{*}{0.00} \\
\hline & $\begin{array}{l}\text { Transform } \\
\text { Random }\end{array}$ & 7 & 0.07 & -0.16 & 0.30 & 2327 & 0.55 & 0.07 & & & \\
\hline \multirow[t]{2}{*}{ DS-ST } & $\begin{array}{l}\text { Transform } \\
\text { Fixed }\end{array}$ & 5 & 0.22 & 0.18 & 0.26 & 2112 & 0.00 & 0.22 & \multirow{2}{*}{74.84} & \multirow{2}{*}{4} & \multirow{2}{*}{0.00} \\
\hline & \begin{tabular}{|l} 
Transform \\
Random \\
\end{tabular} & 5 & 0.10 & -0.15 & 0.34 & 2112 & 0.77 & 0.10 & & & \\
\hline \multirow[t]{2}{*}{ CR-RB } & $\begin{array}{l}\text { Transform } \\
\text { Fixed }\end{array}$ & 4 & 0.10 & 0.04 & 0.16 & 1068 & 0.00 & 0.10 & \multirow{2}{*}{42.39} & \multirow{2}{*}{3} & \multirow{2}{*}{0.00} \\
\hline & $\begin{array}{l}\text { Transform } \\
\text { Random }\end{array}$ & 4 & 0.02 & -0.26 & 0.30 & 1068 & 0.90 & 0.02 & & & \\
\hline \multirow[t]{2}{*}{ CH-PF } & $\begin{array}{l}\text { Transform } \\
\text { Fixed }\end{array}$ & 10 & 0.39 & 0.34 & 0.43 & 1515 & 0.00 & 0.39 & \multirow{2}{*}{71.44} & \multirow{2}{*}{9} & \multirow{2}{*}{0.00} \\
\hline & $\begin{array}{l}\text { Transform } \\
\text { Random }\end{array}$ & 10 & 0.36 & 0.21 & 0.49 & 1515 & 0.00 & $0.36 * *$ & & & \\
\hline \multirow[t]{2}{*}{ CH-ST } & $\begin{array}{l}\text { Transform } \\
\text { Fixed }\end{array}$ & 6 & 0.58 & 0.54 & 0.61 & 1298 & 0.00 & 0.58 & 14036 & & \\
\hline & $\begin{array}{l}\text { Transform } \\
\text { Random }\end{array}$ & 6 & 0.57 & 0.30 & 0.76 & 1298 & 0.00 & $0.57 * *$ & 149.36 & 5 & 0.00 \\
\hline RB-PF & $\begin{array}{l}\text { Transform } \\
\text { Fixed } \\
\end{array}$ & 11 & 0.18 & 0.15 & 0.22 & 2867 & 0.00 & 0.18 & 101 801 & 10 & م \\
\hline & $\begin{array}{l}\text { Transform } \\
\text { Random }\end{array}$ & 11 & 0.21 & 0.07 & 0.34 & 2867 & 0.00 & $0.21 * *$ & 101.00 & 10 & 0.00 \\
\hline TC-PF & $\begin{array}{l}\text { Transform } \\
\text { Fixed } \\
\end{array}$ & 7 & 0.34 & 0.31 & 0.38 & 2342 & 0.00 & 0.34 & 16136 & 6 & | \\
\hline & \begin{tabular}{|l} 
Transform \\
Random
\end{tabular} & 7 & 0.23 & -0.02 & 0.45 & 2342 & 0.07 & 0.23 & 101.36 & 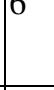 & 0.00 \\
\hline TC-ST & $\begin{array}{l}\text { Transform } \\
\text { Fixed }\end{array}$ & 5 & 0.14 & 0.08 & 0.19 & 1184 & 0.00 & 0.14 & -2969 & 4 & 000 \\
\hline & $\begin{array}{l}\text { Transform } \\
\text { Random }\end{array}$ & 5 & 0.09 & -0.10 & 0.28 & 1184 & 0.35 & 0.09 & 29.69 & 4 & 0.00 \\
\hline RB-ST & $\begin{array}{l}\text { Transform } \\
\text { Fixed } \\
\end{array}$ & 4 & 0.36 & 0.28 & 0.44 & 513 & 0.00 & $0.36 * *$ & -2566 & & \\
\hline & $\begin{array}{l}\text { Transform } \\
\text { Random }\end{array}$ & 4 & 0.44 & 0.17 & 0.65 & 513 & 0.00 & 0.44 & 25.66 & 3 & 0.00 \\
\hline TR-PF & $\begin{array}{l}\text { Transform } \\
\text { Fixed }\end{array}$ & 5 & 0.17 & 0.11 & 0.22 & 1428 & 0.00 & 0.17 & & 4 & م \\
\hline & \begin{tabular}{|l} 
Transform \\
Random
\end{tabular} & 5 & 0.29 & 0.07 & 0.49 & 1428 & 0.01 & $0.29 * *$ & 52.20 & 4 & 0.00 \\
\hline CM-CR & $\begin{array}{l}\text { Transform } \\
\text { Fixed }\end{array}$ & 2 & 0.06 & -0.03 & 0.15 & 511 & 0.16 & 0.06 & 5225 & 1 & مח \\
\hline & \begin{tabular}{|l} 
Transform \\
Random
\end{tabular} & 2 & -0.11 & -0.64 & 0.49 & 511 & 0.74 & -0.11 & 22.05 & $\left.\right|^{1}$ & 0.00 \\
\hline
\end{tabular}

PS: $\mathrm{N}$ is the number of correlation statistic value; Ntotal is the total sample size of correlation; P-Value is the P-value of Effect;

P-Value(Q) the P-value of Q-Value. ** the value is significant. 